\title{
AgI Cloud Seeding Modeling for Hail Suppression of Cold Clouds
}

\author{
Sohaila Javanmard ${ }^{1} \&$ Mahla Karim Pirhayati ${ }^{2}$ \\ 1 Atmospheric Science and Meteorological Research Center (ASMERC), I. R. of Iran Meteorological \\ Organization (IRIMO), Tehran, Iran \\ ${ }^{2}$ Department of Physics, Zanjan University, Zanjan, Iran \\ Correspondence: Sohaila Javanmard, Atmospheric Science and Meteorological Research Center (ASMERC), I. \\ R. of Iran Meteorological Organization (IRIMO), Tehran, P.O. Box 14965-114, Iran. E-mail: \\ sohailajavanmard@gmail.com
}

Received: February 6, 2012 Accepted: February 21, 2012 Online Published: May 18, 2012

doi:10.5539/jgg.v4n2p81 URL: http://dx.doi.org/10.5539/jgg.v4n2p81

\begin{abstract}
In order to assess the performance of operational cloud seeding operations and achieve desirable results, application of numerical cloud model is one of the most important tools. In this paper, effects of silver iodide (AgI) cloud seeding on hail fall have been examined using one dimensional time dependent numerical cloud model. We included 32 microphysical processes with six water substances including water vapor, cloud droplet, cloud ice, rain, snow, and hail (graupel) for natural precipitation and 3 microphysical processes for cloud seeding parameterization. The model has been executed and it is concluded that as AgI introduced into the cloud resulting in graupel/hail mixing ratio reducing about \%53. Heterogeneous nucleation of AgI enhanced the cloud ice, therefore snow increased and rainfall enhanced by melting of snow and cloud ice. On the other hand, cloud ice consumed to produce snow and they did not grow up to reach graupel/hail size, consequently the processes that related to growth of graupel/hail decreased strongly.
\end{abstract}

Keywords: cloud seeding, numerical modeling, hail suppression, AgI

\section{Introduction}

Graupel/hail induces many damages to agriculture, transportation, economical affairs in graupel/hail prone area annually. In order to achieve graupel/hail risk management to decrease induced destruction, application of graupel/hail suppression methods is necessary. The inception of the modern era of weather modification began with the discoveries of Schaefer in 1946 and Vonnegut in 1947, which showed that supercooled liquid water could be converted to ice crystals using either dry ice or silver iodide. According to reports of Weather Modification Organization (WMO), cloud seeding is conducted in more than 29 countries (Jamali et al., 2010).

Application of numerical cloud model is one of the most important tools to assess the seeding effect on hail suppression. Numerical models are the key instrument for weather modification research according to Orville (1996) and Garstang et al. (2005). Simpson et al. (1965) and Hsie et al. (1980) simulated the effect of artificial seeding in cumulus cloud models and found good results.

Javanmard (1995) improved Ogura and Takahashi (1971) one dimensional cloud model in some microphysical processes. The model includes nine cloud microphysical processes which have been parameterized with four water substances including water vapor, cloud droplet, raindrop and graupel/hail. Lin et al. (1983) created a two-dimensional, time-dependent cloud model with bulk parameterization. In this model, 32 microphysical processes were parameterized with six water substances including water vapor, cloud droplet, cloud ice, raindrop, snow and graupel/hail. Zhen and Heng- Chi (2010) model is a three-dimensional non-hydrostatic mesoscale model MM5 was used to test the extra-area effects of stratiform cloud seeding with silver iodide. In this paper, we present a new one dimensional AgI seeding modeling with bulk microphysics parameterization which have been developed to examine the effects of Silver Iodide seeding. The structure of numerical cloud model will be described in section 2. In section 3, the numerical procedure will be explained and in the last section, outputs of model including mixing ratios of raindrop $\left(\mathrm{Q}_{\mathrm{r}}\right)$, snow $\left(\mathrm{Q}_{\mathrm{s}}\right)$, graupel/hail $\left(\mathrm{Q}_{\mathrm{G}}\right)$, temperature difference between cloud and environment (TT), and rainfall intensity at ground surface (GPR) will be compared before and after seeding. 


\section{Hail Suppression Model}

\subsection{Microphysical Processes of Model}

Lin et al. model (1983) is a two-dimensional, time-dependent cloud model which is used to simulate a moderate intensity thunderstorm. In this model six forms of water substances (water vapor, cloud water, cloud ice, rain, snow and graupel/hail) are simulated that are presented in Table 1 and 32 microphysical processes are considered as shown in Figure 1. Zhen and Heng Chi model is a Fifth-Generation NCAR/Penn State Mesoscale Model (MM5) (the Fifth-Generation National Center for Atmospheric Research (NCAR)/Penn State Mesoscale Model) that has been used to investigate the extra-area effects of AgI seeding on stratiform clouds performed at the supercooled layer. In hail suppression model, microphysical parameterization of natural precipitation process is based on Lin et al. (1983), and cloud seeding parameterization is based on Zhen and Heng-Chi (2010). When $\mathrm{AgI}$ are inserted to the cloud base, it affects on six cloud hydrometeors including cloud droplet, raindrop, snow and graupel/hail mixing ratios via contact and deposition nucleation, transportation from rain drop to snow and droplet to cloud ice due to seeding. The processes in the model are described as follows.

Table 1. Microphysical processes in Lin et al. model (1983)

\begin{tabular}{|c|c|}
\hline Notation & Description \\
\hline $\mathrm{P}_{\mathrm{CON}}$ & Condensation \\
\hline $\mathrm{P}_{\mathrm{IMLT}}$ & Melting of cloud ice to form cloud water, $\mathrm{T} \geq \mathrm{T}_{0}$ \\
\hline $\mathrm{P}_{\mathrm{IACRS}} / \mathrm{P}_{\mathrm{IACRG}}$ & Accretion of rain by cloud ice produces snow or graupel \\
\hline $\mathrm{P}_{\mathrm{NUA}} / \mathrm{P}_{\mathrm{NUH}} / \mathrm{P}_{\mathrm{NUF}}$ & Nucleation for producing water vapor to ice nuclei \\
\hline $\mathrm{P}_{\text {RAUT }}$ & Autoconversion of cloud water to form rain \\
\hline $\mathrm{P}_{\mathrm{CEVP}}$ & Evaporation of cloud water \\
\hline $\mathrm{P}_{\mathrm{REVP}}$ & Evaporation of rain \\
\hline $\mathrm{P}_{\mathrm{RACW}}$ & Accretion of cloud water by rain \\
\hline $\mathrm{P}_{\mathrm{RACIG}} / \mathrm{P}_{\mathrm{RACIS}}$ & Accretion of cloud ice by rain produces snow or graupel \\
\hline $\mathrm{P}_{\text {IACRS }} / \mathrm{P}_{\text {IACRG }}$ & Accretion of rain by cloud ice produces snow or graupel \\
\hline $\mathrm{P}_{\mathrm{SACW}}$ & Accretion of cloud water by snow \\
\hline $\mathrm{P}_{\mathrm{SACRS}} / \mathrm{P}_{\mathrm{SACRG}}$ & Accretion of rain by snow produces snow or graupel \\
\hline $\mathrm{P}_{\text {IDEP }}$ & Deposition growth of cloud ice \\
\hline $\mathrm{P}_{\mathrm{SACI}}$ & Accretion of cloud ice by snow \\
\hline $\mathrm{P}_{\mathrm{SAUT}}$ & Autoconversion of cloud ice to form snow \\
\hline $\mathrm{P}_{\mathrm{SFW}}$ & Bergeron process (deposition and riming)- transfer of cloud water to form snow \\
\hline $\mathrm{P}_{\mathrm{SFI}}$ & Transformation of cloud ice to snow through Bergeron process embryos \\
\hline $\mathrm{P}_{\mathrm{SDEP}}$ & Deposition growth of snow \\
\hline $\mathrm{P}_{\mathrm{SSUB}}$ & Sublimation of snow \\
\hline $\mathrm{P}_{\mathrm{SMLT}}$ & Melting of snow to form rain \\
\hline $\mathrm{P}_{\mathrm{GAUT}}$ & Autoconversion of snow to form graupel \\
\hline $\mathrm{P}_{\mathrm{GFR}}$ & Probabilistic freezing of rain to form graupel \\
\hline $\mathrm{P}_{\mathrm{GACW}}$ & Accretion of cloud water by graupel \\
\hline $\mathrm{P}_{\mathrm{GACR}}$ & Accretion of rain by graupel \\
\hline $\mathrm{P}_{\mathrm{GACS}}$ & Accretion of snow by graupel \\
\hline $\mathrm{P}_{\mathrm{GMLT}}$ & Melting of graupel to form rain \\
\hline $\mathrm{P}_{\mathrm{GSUB}}$ & Sublimation of graupel \\
\hline $\mathrm{P}_{\mathrm{IEVP}}$ & Evaporation of cloud ice \\
\hline $\mathrm{P}_{\mathrm{GDRY}} / \mathrm{P}_{\mathrm{GWET}}$ & Dry/ wet growth of graupel \\
\hline $\mathrm{P}_{\mathrm{RACS}}$ & Accretion of snow by rain \\
\hline
\end{tabular}




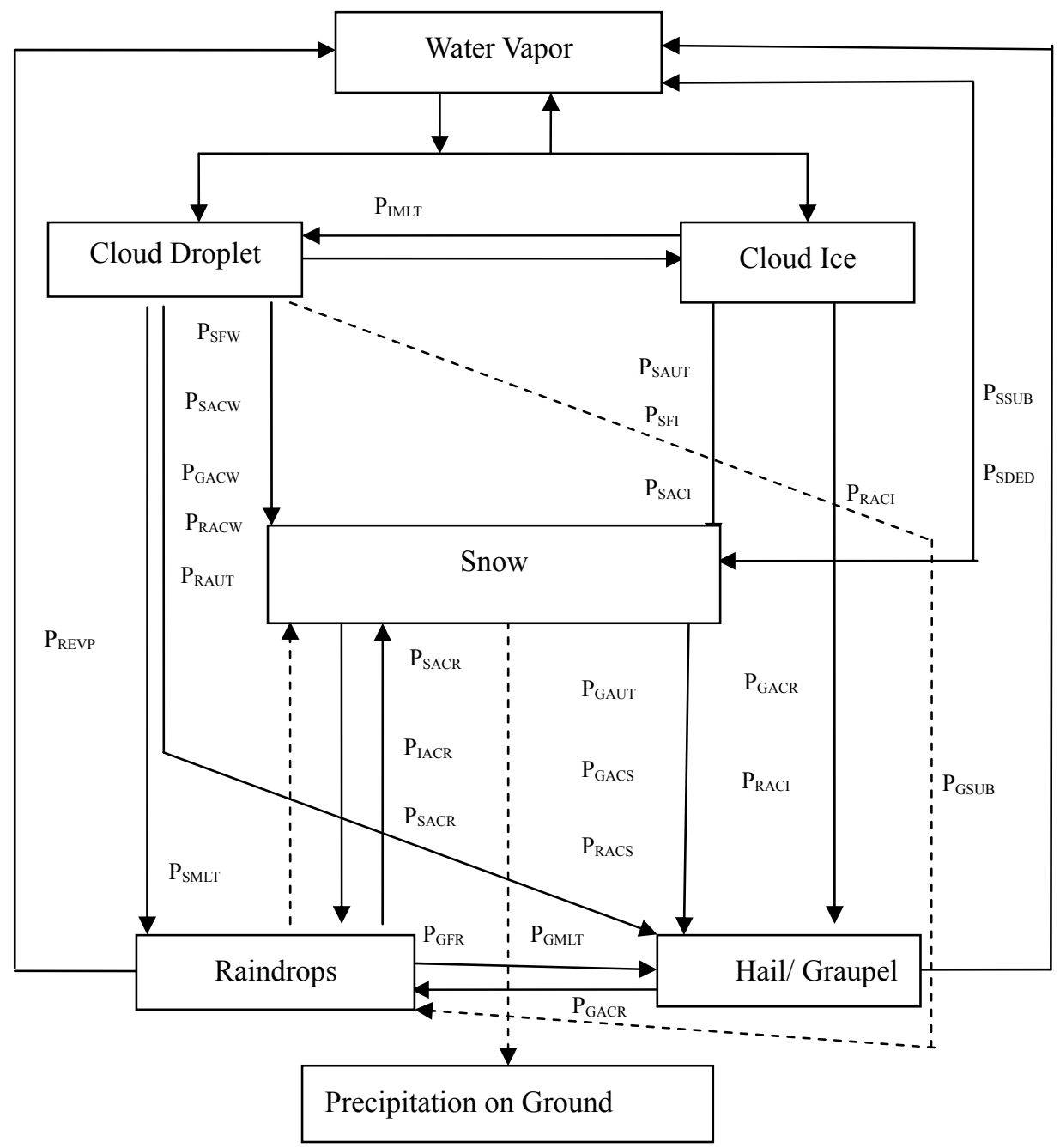

Figure 1. Microphysical processes in Lin et al. model (1983)

\subsubsection{Interactions with Raindrop}

When a supercooled raindrop captures an active ice nucleus, contact nucleation occurs. The number concentration of active ice nuclei $N_{a R}(\Delta T)$ captured by raindrops at a supercooling $\Delta T$ $\left(\Delta T=T_{0}-T, T_{0}=273.15 K\right)$ is calculated as

$$
N_{a R}(\Delta T)=\left\{-\left(S_{B R}+S_{I R}\right)\left[\frac{N_{a}(\Delta T)}{N_{a}\left(20^{\circ} C\right)}\right] \Delta t\right\} m_{s}^{-1}
$$

Where $N_{a}(\Delta T) / N_{a}\left(20^{\circ} \mathrm{C}\right)$ is the fraction of the AgI particles activated at a supercooling $\Delta T, S_{B R}$ is the sink of $\mathrm{AgI}$ due to raindrop by Brownian collection and $S_{I R}$ is the sink of $\mathrm{AgI}$ due to raindrop by inertial compact collection. The total number of raindrops $N_{R}$ imposed is

$$
N_{R}=\frac{n_{o \mathrm{R}}}{\lambda_{R}} \exp \left(-0.01 \lambda_{R}\right)
$$

The transformation rate from rainwater to snow due to seeding is

$$
P_{I S R}=Q_{r} \frac{N_{a R}(\Delta T)}{\Delta t N_{R}}
$$

where $Q_{r}$ is the mixing ratio of raindrops. 


\subsubsection{Interactions with Cloud Water}

Contact freezing nucleation: Following the same procedure outlined in the previous section, $P_{C S W C}$, the rate at which cloud water transforms to cloud ice due to contact nucleation may be written as

$$
P_{C S W C}=Q_{C} \frac{N_{a W}(\Delta T)}{\Delta t N_{W}}
$$

Where $N_{a W}(\Delta T)$ is the number of active AgI nuclei captured by cloud droplets and it is defined by

$$
N_{a W}(\Delta T)=\left\{-\left(S_{B W}+S_{I W}\right)\left[\frac{N_{a}(\Delta T)}{N_{a}\left(20^{\circ} C\right)}\right] \Delta t\right\} m_{s}^{-1}
$$

where $S_{B W}$ is the sink of AgI due to droplet by Brownian collection and $S_{I W}$ is the sink of AgI due to droplet by inertial compact collection.

Deposition nucleation: In the cloudy environment, we assume the relative humidity is $100 \%$ with respect to weighted- mean saturation mixing ratio, weighted with respect to the amounts of cloud water and cloud ice. If relative humidity is less than $100 \%$, the cloud will evaporate instantaneously to supply the vapor needed to keep relative humidity $100 \%$. Under this assumption, the activation of deposition nuclei depletes the cloud water in the cloudy environment. Deposition nucleation, as modeled, also includes sorption nucleation. The number of AgI particles active as deposition nuclei at a supercooling $\Delta T$ is computed as

$$
N_{a D}(\Delta T)=X_{S}\left[\frac{N_{a}(\Delta T)}{N_{a}\left(20^{\circ} C\right)}\right] m_{s}^{-1}
$$

Seeding enhances the Bergeron- Findeisen process through deposition nucleation, and will transform the cloud water to cloud ice. The rate $\left(P_{C S W D}\right)$ is

$$
P_{C S W D}=N_{a D}(\Delta T) A^{\prime} m_{S}^{B}
$$

$A^{\prime}$ and $B^{\prime}$ are parameters in Bergeron process.

\subsection{Dynamical Processes of Model}

Ogura and Takahashi model is a time dependent and one dimensional model with bulk parameterization. In this model, the cloud is modeled as a circular air column with a time dependent radius in an environment at rest. All dynamical equations have been formulated in a one dimensional space based on Asai and Kasahara (1967). In Ogura and Takahashi model, nine microphysical processes has been parameterized with four water substances including water vapor, cloud droplet, raindrop and graupel/hail. Jamali and Javanmard (2003) have improved the microphysical parameterization in the Ogura and Takahashi model. The most important features of the Developed Ogura and Takahashi (DOT) model could be defined as the inclusion of Kessler parameterization concepts in a warm rain process, Bigg's freezing and terminal velocities of rain water and graupel/hail particles. In hail suppression model, dynamic and thermodynamic equations are based on DOT model that cloud ice and snow are included.

The equation of the vertical component of velocity in a cylindrical coordinate may be written as

$$
\frac{\partial \mathrm{w}}{\partial t}=-w \frac{\partial_{W}}{\partial_{Z}}-\frac{2 \alpha^{2}}{a} w|w|+\frac{2}{a} \tilde{u}_{a}\left(w-\tilde{w}_{a}\right)+g \frac{T_{V}-T_{V 0}}{T_{V O}}-g\left(Q_{C}+Q_{r}+Q_{i}+Q_{G}+Q_{S}+X_{S}\right)
$$

The first term in the right-hand side of Eq. (1) represents the vertical advection, the second term the lateral eddy exchange, the third term the dynamic entertainment that is required to satisfy the mass continuity between the cloud and the environment, the fourth term the buoyancy, and the last term the drag force that is assumed to be provided by the weight of cloud droplets, raindrops, cloud ice, graupel/hail, snow, and AgI. In this equation, $u_{a}$ which is the value of $u_{a}$ at $\mathrm{r}=\mathrm{a}$, is determined by the following equation with the boundary condition that $\mathrm{w}=0$ at $\mathrm{z}=0$,

$$
\frac{2}{a} \tilde{u}_{a}+\frac{1}{\rho_{a 0}} \frac{\partial}{\partial z}\left(\rho_{a 0} \bar{w}\right)=0
$$


The equations temperature, continuity for water vapor, cloud droplets, cloud ice, raindrops, snow, graupel/hail, and $\mathrm{AgI}$ particles, respectively, are given as follows

$$
\begin{gathered}
\frac{\partial T}{\partial t}=-w \frac{\partial T}{\partial Z}+\frac{2 \alpha^{2}}{a}|W|\left(\mathrm{T}_{0}-\mathrm{T}\right)+\frac{2}{a} \tilde{u}_{a}\left(\mathrm{~T}-\tilde{\mathrm{T}}_{\mathrm{a}}\right)+\left(\frac{L_{V}}{C_{P}}\right)\left(\mathrm{P}_{1}-\mathrm{P}_{6}-\mathrm{P}_{\mathrm{REVP}}\right)+\left(\frac{L_{S}}{C_{P}}\right)\left(-\mathrm{P}_{\mathrm{IEVP}}++\mathrm{P}_{\mathrm{NUA}}+\right. \\
\left.\mathrm{P}_{\mathrm{IDEP}}-\mathrm{P}_{\mathrm{SSUB}}-\mathrm{P}_{\mathrm{GSUB}}+\mathrm{P}_{\mathrm{SDEP}}+\mathrm{P}_{\mathrm{ISR}}\right)+\left(\frac{L_{f}}{C_{P}}\right)\left(-\mathrm{P}_{\mathrm{IMLT}}+\mathrm{P}_{\mathrm{SFW}}+\mathrm{P}_{\mathrm{IACRS}}+\mathrm{P}_{\mathrm{SACRS}}+\mathrm{P}_{\mathrm{SACW}}-\mathrm{P}_{\mathrm{SMLT}}+\right. \\
\left.\mathrm{P}_{\mathrm{GFR}}+\mathrm{P}_{\mathrm{GACW}}+\mathrm{P}_{\mathrm{GACR}}+\mathrm{P}_{\mathrm{SACRG}}+\mathrm{P}_{\mathrm{IACRG}}-\mathrm{P}_{\mathrm{GMLT}}+\mathrm{P}_{\mathrm{NUH}}+\mathrm{P}_{\mathrm{NUF}}+\mathrm{P}_{\mathrm{CSWC}}+\mathrm{P}_{\mathrm{CSWD}}\right) \\
\frac{\partial Q_{V}}{\partial t}=-\mathrm{w} \frac{\partial Q_{V}}{\partial Z}+\frac{2 \alpha^{2}}{a}|w|\left(\mathrm{Q}_{\mathrm{V} 0}-\mathrm{Q}_{\mathrm{V}}\right)+\frac{2}{a} \tilde{u}_{a}\left(\mathrm{Q}_{\mathrm{V}}-\tilde{\mathrm{Q}}_{\mathrm{Va}}\right)+\mathrm{P}_{\mathrm{V}} \\
\frac{\partial Q_{C}}{\partial t}=-\mathrm{w} \frac{\partial Q_{C}}{\partial Z}-\frac{2 \alpha^{2}}{a}|w|\left(\mathrm{Q}_{\mathrm{C}}\right)+\frac{2}{a} \tilde{u}_{a}\left(\mathrm{Q}_{\mathrm{C}}-\tilde{\mathrm{Q}}_{\mathrm{Ca}}\right)+\mathrm{P}_{\mathrm{C}} \\
\frac{\partial Q_{r}}{\partial t}=-\mathrm{w} \frac{\partial Q_{r}}{\partial Z}+\mathrm{w} \frac{\partial V_{W}}{\partial Z}-\frac{2 \alpha^{2}}{a}|w|\left(\mathrm{Q}_{\mathrm{r}}\right)+\frac{2}{a} \tilde{u}_{a}\left(\mathrm{Q}_{\mathrm{r}}-\tilde{\mathrm{Q}}_{\mathrm{ra}}\right)+\mathrm{P}_{\mathrm{r}} \\
\frac{\partial Q_{i}}{\partial t}=-\mathrm{w} \frac{\partial Q_{i}}{\partial Z}-\frac{2 \alpha^{2}}{a}|w|\left(\mathrm{Q}_{\mathrm{i}}\right)+\frac{2}{a} \tilde{u}_{a}\left(\mathrm{Q}_{i}-\tilde{\mathrm{Q}}_{\mathrm{ia}}\right)+\mathrm{P}_{i} \\
\frac{\partial Q_{S}}{\partial t}=-\mathrm{w} \frac{\partial Q_{S}}{\partial Z}+\mathrm{w} \frac{\partial V_{S}}{\partial Z}-\frac{2 \alpha^{2}}{a}|w|\left(\mathrm{Q}_{\mathrm{S}}\right)+\frac{2}{a} \tilde{u}_{a}\left(\mathrm{Q}_{\mathrm{S}}-\tilde{\mathrm{Q}}_{\mathrm{Sa}}\right)+\mathrm{P}_{S} \\
\frac{\partial Q_{G}}{\partial t}=-\mathrm{w} \frac{\partial Q_{G}}{\partial Z}+\mathrm{w} \frac{\partial V_{G}}{\partial Z}-\frac{2 \alpha^{2}}{a}|w|\left(\mathrm{Q}_{\mathrm{G}}\right)+\frac{2}{a} \tilde{u}_{a}\left(\mathrm{Q}_{G}-\tilde{\mathrm{Q}}_{\mathrm{Ga}}\right)+\mathrm{P}_{G} \\
\frac{\partial X_{S}}{\partial t}=-\mathrm{w} \frac{\partial X_{S}}{\partial Z}-\frac{2 \alpha^{2}}{a}|w|\left(\mathrm{X}_{\mathrm{S}}\right)+\frac{2}{a} \tilde{u}_{a}\left(\mathrm{X}{ }_{S}-\tilde{\mathrm{X}}_{\mathrm{S}}\right)-\left(\mathrm{S}_{\mathrm{BW}}+\mathrm{S}_{\mathrm{BR}}+\mathrm{S}_{\mathrm{IW}}+\mathrm{S}_{\mathrm{IR}}+\mathrm{S}_{\mathrm{DV}}\right)
\end{gathered}
$$

where VW, VS and VG are terminal velocity of raindrop, snow, and graupel/hail, respectively, and PV, PC, Pr, $\mathrm{Pi}$, PS and PG are rate of production of water vapor, cloud droplet, raindrop, cloud ice, snow, and graupel/hail as follows

$$
\begin{gathered}
V_{W}=\frac{a \Gamma(4+b)}{6 \lambda_{R}^{b}}\left(\frac{\rho_{o}}{\rho}\right)^{1 / 2} \\
V_{S}=\frac{C_{S} \Gamma(D+4)}{6 \lambda_{R}^{D}}\left(\frac{\rho_{o}}{\rho}\right)^{1 / 2} \\
V_{G}=\frac{\Gamma(4.5)}{6 \lambda_{I}^{0.5}}\left(\frac{4 g \rho_{I}}{3 C_{D} \rho}\right)^{1 / 2} \\
P_{V}=P_{6}+P_{R E V P}+P_{S S U B}+P_{G S U B}+P_{I E V P}-\left(P_{1}+P_{S D E P}+P_{I D E P}+P_{N U A}\right) \\
P_{\mathrm{i}}+P_{\mathrm{NUH}}+P_{N U F}+P_{N U A}+P_{I D E P}-\left(P_{R A C I S}+P_{S A U T}+P_{S A C I}+P_{S F I}+P_{R A C I G}+P_{I E V P}+P_{I M L T}\right) \\
P_{r}=P_{\mathrm{RAUT}}+P_{R A C W}+P_{S A C W}+P_{G A C W}+P_{S M L T}+P_{G M L T}- \\
\left(P_{R E V P}+P_{I A C R S}+P_{S A C R S}+P_{I A C R G}+P_{G F R}+P_{S A C R G}+P_{G A C R}\right)
\end{gathered}
$$




$$
\begin{gathered}
P_{S}=P_{\mathrm{SAUT}}+P_{S A C I}+P_{S A C W}+P_{S F W}+P_{S F I}+P_{R A C I S}+P_{I A C R S}+P_{S A C R S}+P_{S D E P}- \\
\left(P_{R A C S}+P_{G A C S}+P_{G A U T}+P_{S S U B}+P_{S M L T}\right) \\
P_{G}=P_{\mathrm{RACIG}}+P_{R A C S}+P_{G A U T}+P_{I A C R G}+P_{G F R}+P_{S A C R G}+P_{G D R Y}+P_{G W E T}+P_{G A C S}-\left(P_{G S U B}+P_{G M L T}\right)
\end{gathered}
$$

\section{Numerical Calculation Method in Model}

The numerical calculation method in model is based on DOT model. This is a coupled, one-dimensional cloud model with balk microphysical parameterization. The space increment along the vertical direction $(\Delta z)$ is $250 \mathrm{~m}$ and the time increment $(\Delta t)$ is $5 \mathrm{~s}$. The prognostic equations of vertical velocity $(\mathrm{w})$, temperature $(\mathrm{T})$, mixing ratios of water vapor $(\mathrm{QV})$, mixing ratios of cloud droplets $(\mathrm{QC})$, mixing ratios of cloud ice (Qi), mixing ratios of rain water (Qr), mixing ratios of snow (QS), mixing ratios of graupel/hail (QG), and mixing ratio of AgI (XS) are solved by a finite difference method. The numerical method used is forward difference. All spatial derivatives, except for those in the advection terms of the equations, have been calculated from centered difference.

w, T, QV, QC, Qi, Qr, QS, QG and XS are zero at ground surface and at the top of the atmosphere they are assumed to be $15 \mathrm{~km}$ from the surface. Initial motion in atmosphere starts at a distance of $2 \mathrm{Km}$ above the surface by a small updraft movement as follows

$$
w_{t=0}=\Delta w\left(\frac{z}{z_{0}}\right)\left(2-\frac{z}{z_{0}}\right)
$$

Where $\Delta w=1 \mathrm{~m} / \mathrm{s}$ and $z_{0}=1 \mathrm{~km}$

Temperature at ground surface is $25^{\circ} \mathrm{C}$ and its lapse rate is $6.3{ }^{\circ} \mathrm{C} / \mathrm{km}$ and more than $10 \mathrm{~km}$ is constant. Relative humidity at ground surface is $100 \%$ and it decreases $5 \%$ per kilometer.

The calculation procedure is

1) $\tilde{u}_{a}$ is calculated from $w$ using Eq. (9);

2) VW, VS, and VG are calculated using Eqs. (18) to (20);

3) The quantities of w, T, QV, QC, Qi, Qr, QS, QG and XS are calculated considering the dynamical terms in the prognostic Eqs. (8) through (17);

4) In this step, QVS and QiS which are saturation mixing ratios over water and ice, respectively, as a function of temperature are given as follows

$$
\begin{aligned}
Q_{V S} & =3.8 P^{-1} 10 \frac{7.5(T-273)}{T-6} \\
Q_{i S} & =3.8 P^{-1} 10 \frac{9.5(T-273)}{T-8}
\end{aligned}
$$

where $P$ is the atmospheric pressure. These calculations include different states of $T \frac{\geq}{<} 273, Q_{V} \leq Q_{V S}, Q_{V} \leq Q_{>}$, $Q_{i S}<Q_{V}<Q_{V S}, Q_{r} \leq 0, Q_{G} \leq 0$, and $Q_{S} \leq 0$. Sometimes, two or three physical processes occur simultaneously. For example, in unsaturated air, evaporation of cloud droplet, rain drops, cloud ice, snow, and graupel/hail occurs simultaneously. In another case, it is assumed that, at first, cloud droplets would be evaporated. If the air is still unsaturated, rain, cloud ice, snow, and graupel/hail will be evaporated. The condition that the whole evaporation should not exceed water vapor amount should always be satisfied.

5) In the next step, the values of $T, Q_{V}, Q_{C}, Q_{i}, Q_{r}, Q_{S}, Q_{G}$ and $X_{S}$ are calculated considering the sources and sinks terms $\left(P_{1} \ldots P_{35}\right)$. One-time increment calculation should be completed by performing steps (1) through (5).

The programming language used for hail suppression model is FORTRAN and Tecplot and Excel software is used to draw model outputs. 


\section{Results}

In this section, we will compare the output graphs including the contours of mixing ratios of raindrop, mixing ratios of snow, mixing ratios of graupel/hail, temperature difference between cloud and environment, and the graphs of source, sink terms, and rainfall intensity at ground surface amounts versus time before and after seeding. AgI introduced into the cloud at height about $6.5 \mathrm{~km}$ above the surface (temperature less than -20 degree Celsius) within 30 minutes after cloud formation with mixing ratio about $2.5^{*} 10^{-9} \mathrm{gg}^{-1}$ (KarimPirhayati, 2010).

\subsection{Mixing Ratio of Rainwater $\left(Q_{r}\right)$}

The contours of rain water mixing ratio versus height and time are shown in Figuress $2 a$ and $2 b$, in which the maximum values of rain water mixing ratio are $5.9 \mathrm{gkg}^{-1}$ and $5.41 \mathrm{gkg}^{-1}$ before and after seeding, respectively, and their minimum values are $0.4 \mathrm{gkg}^{-1}$.

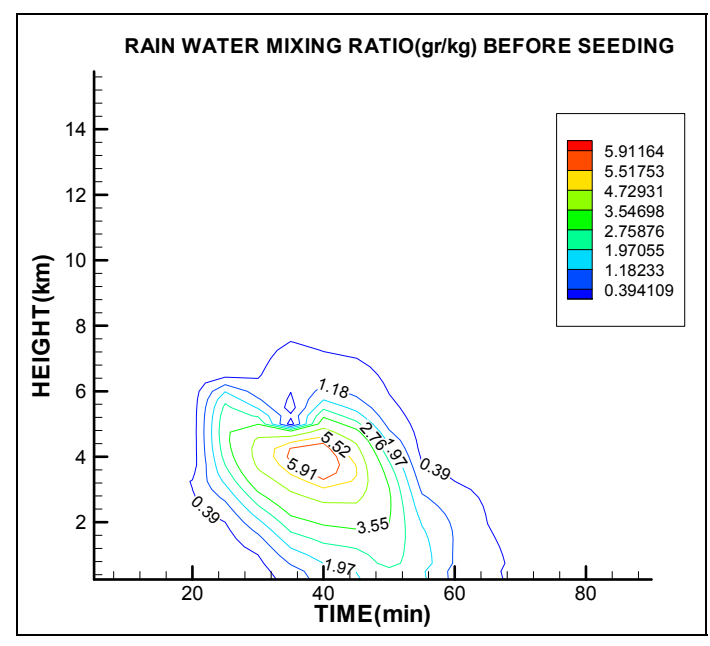

(a)

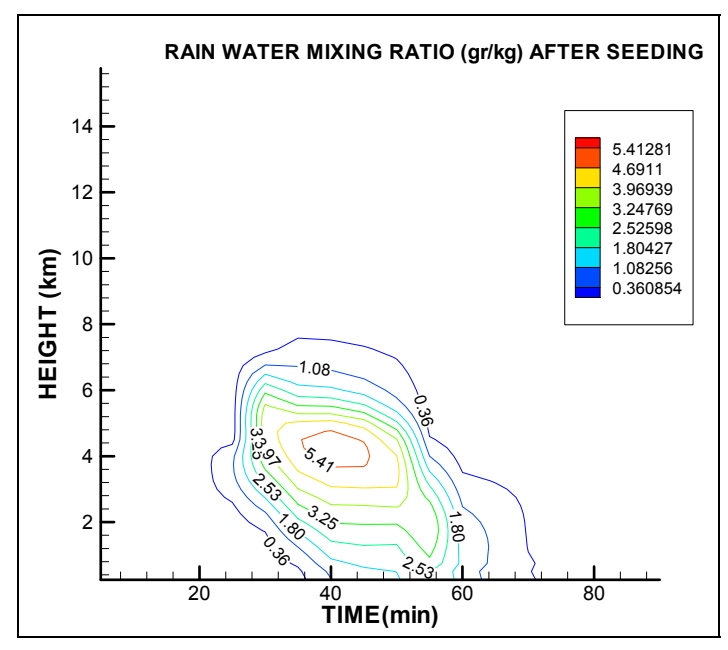

(b)

Figure 2. Comparison of the rain water mixing ratio changes with height and time (a) before seeding and (b) after seeding

From Figures $3 \mathrm{a}$ and $3 \mathrm{~b}$, it could be concluded that the most effective rain production source term is $P_{G A C W}$ (accretion of cloud water by graupel/hail) before seeding and they are $P_{R A C W}, P_{S A C W}$, and $P_{G A C W}$ (Accretion of cloud water by rain, accretion of cloud water by snow, and accretion of cloud water by graupel) after seeding. Considering Figures $4 \mathrm{a}$ and $4 \mathrm{~b}$, we have observed that the most effective sink terms are $P_{S A C R G}, P_{G A C R}$ and $P_{G F R}$ (Accretion of rain by snow produces graupel, accretion of rain by graupel, and probabilistic freezing of rain to form graupel) before seeding and they are $P_{R E V P}$ and $P_{G A C R}$ (Evaporation of rain and accretion of rain by graupel) after seeding. Rainfall intensity enhances by increasing source terms and decreasing sink terms after seeding.

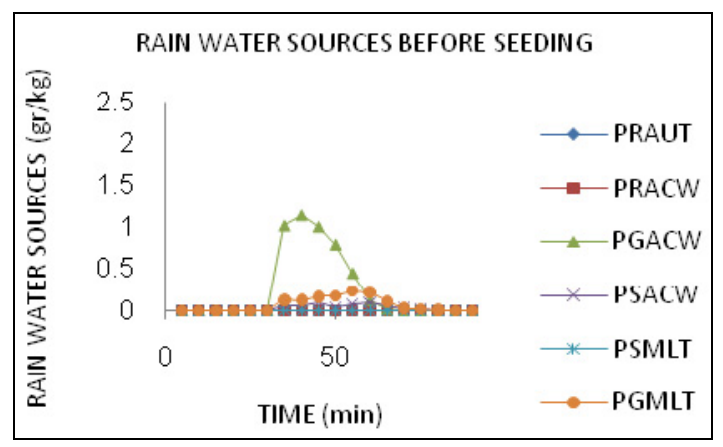

(a)

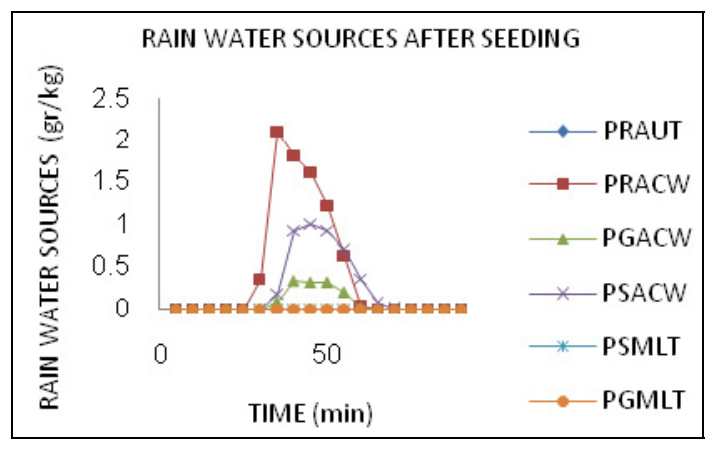

(b)

Figure 3. Comparison of the rain producing source terms (a) before seeding and (b) after seeding 


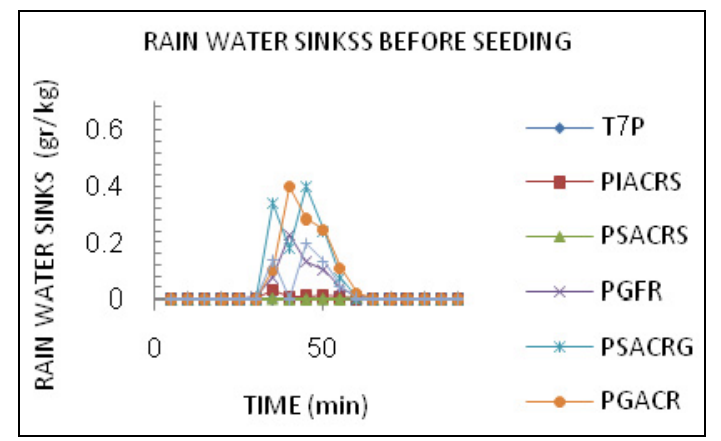

(a)

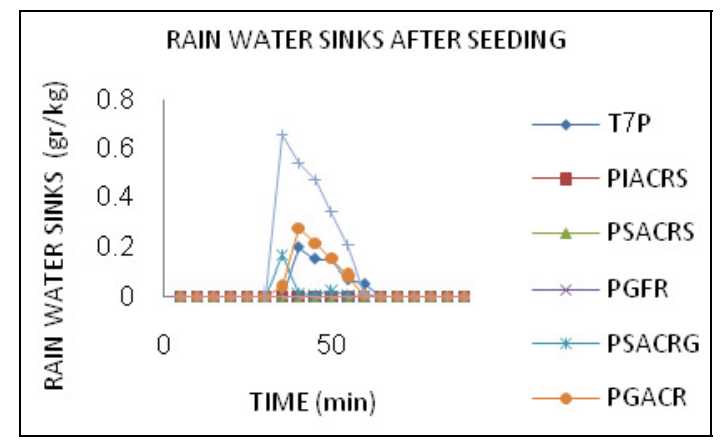

(b)

Figure 4. Comparison of the rain sink terms (a) before seeding and (b) after seeding

\subsection{Mixing Ratio of Snow $\left(Q_{S}\right)$}

The contours of snow mixing ratio versus height and time are shown in Figures $5 \mathrm{a}$ and $5 \mathrm{~b}$, in which the maximum values of snow mixing ratio before and after seeding are $0.56 \mathrm{gkg}^{-1}$ and $0.61 \mathrm{gkg}^{-1}$, respectively.

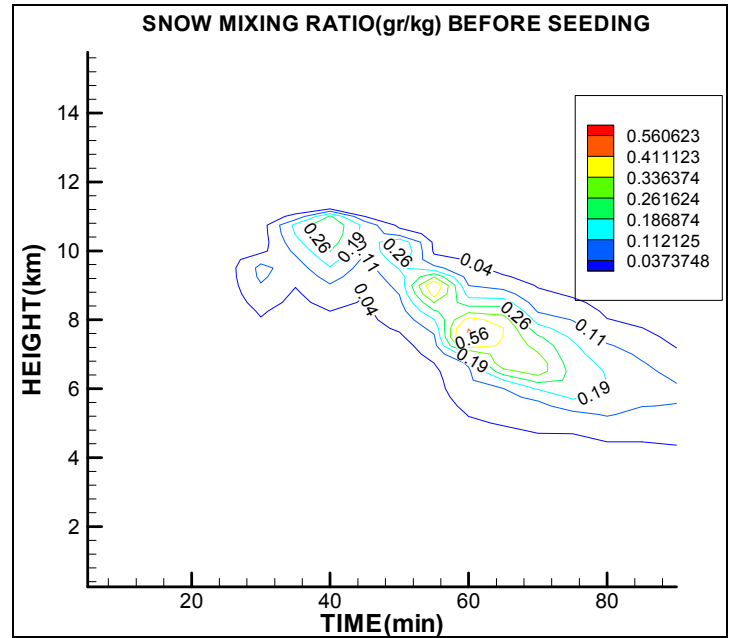

(a)

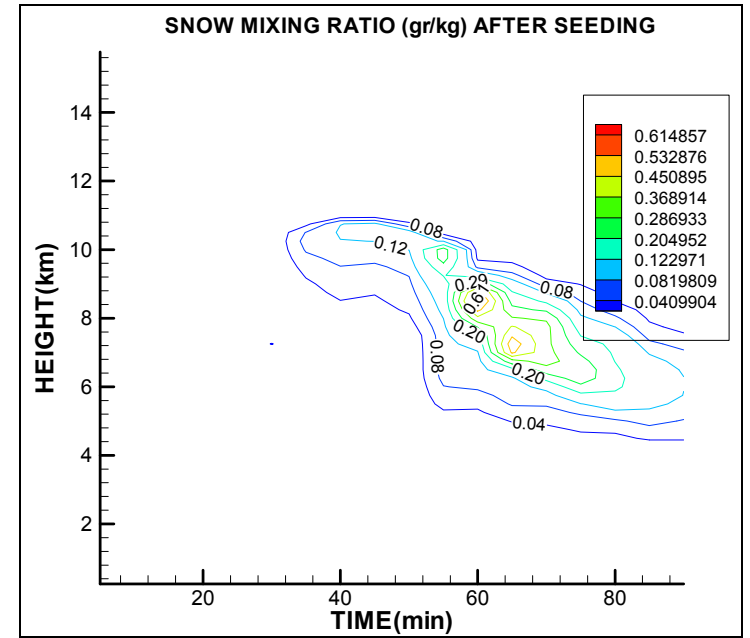

(b)

Figure 5. Comparison of the snow mixing ratio changes with height and time

(a) before seeding and (b) after seeding

We have studied these differences in view of source and sink terms. From Figures $6 \mathrm{a}$ and $6 \mathrm{~b}$, it could be concluded that the most effective snow production source term is $P_{S A C W}$ (Accretion of cloud water by snow) before and after seeding, but its amount is 10 times greater after seeding. Comparison of Figures $7 \mathrm{a}$ and $7 \mathrm{~b}$ shows that the most effective sink terms are $P_{R A C S G}, P_{G A C S}$, and $P_{S S U B}$ (Accretion of snow by rain, accretion of snow by graupel, and sublimation of snow) before seeding and they are $P_{R A C S G}$ and $P_{G A U T}$ (Accretion of snow by rain and Autoconversion of snow to form graupel) after seeding. After seeding, increased cloud ice, thus the processes to convert cloud ice to snow enhance. 


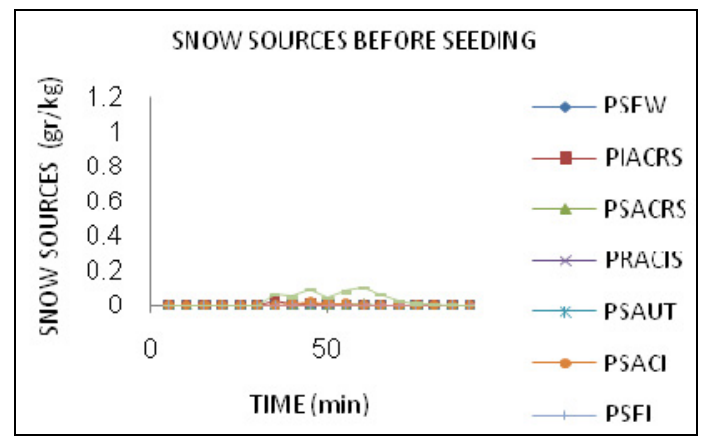

(a)

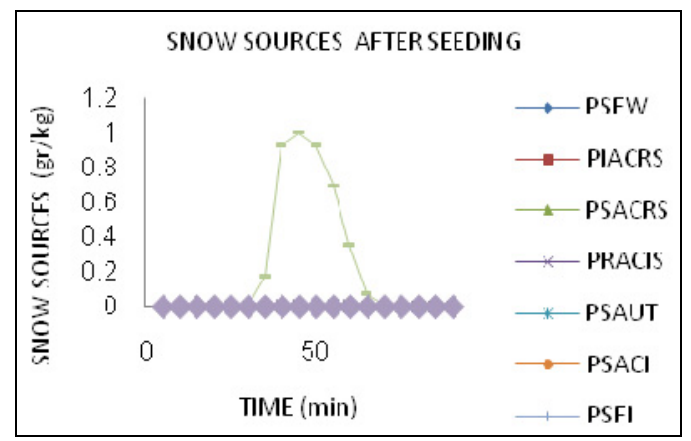

(b)

Figure 6. Comparison of the snow producing source terms (a) before seeding and (b) after seeding

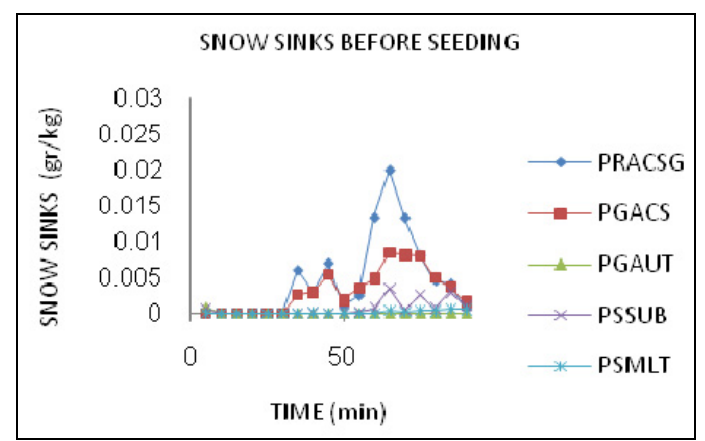

(a)

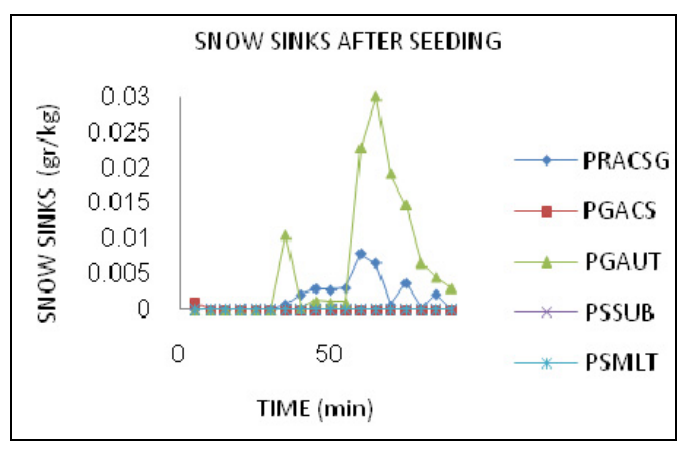

(b)

Figure 7. Comparison of the snow sink terms (a) before seeding and (b) after seeding

\subsection{Mixing Ratio of Graupel/ Hail $\left(Q_{G}\right)$}

The contours of graupel/hail mixing ratio versus height and time are shown in Figures $8 \mathrm{a}$ and $8 \mathrm{~b}$, in which the maximum values of graupel/hail mixing ratio are $7.1 \mathrm{gkg}^{-1}$ and $3.3 \mathrm{gkg}^{-1}$ before and after seeding, respectively. This is the most important feature of AgI seeding which has been considerable effect on reducing graupel/hail mxing ratio about $3.8 \mathrm{gkg}^{-1}$ which demonstrated the graupel/hail suppression process very well.

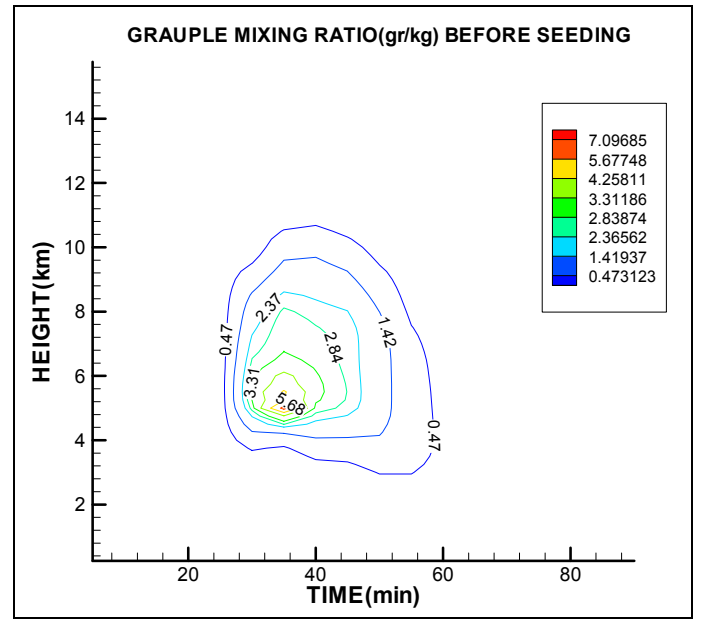

(a)

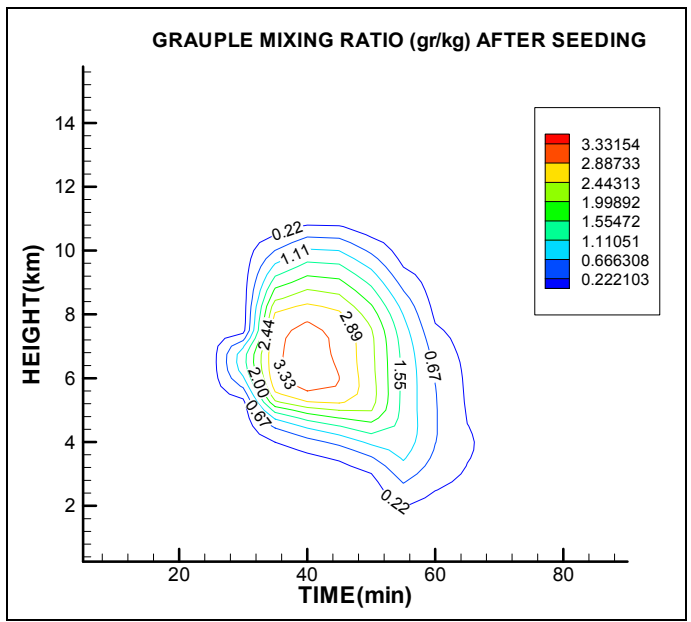

(b)

Figure 8. Comparison of the graupel/hail mixing ratio changes with height and time (a) before seeding and (b) after seeding 
Regarding the microphysical process in graupel/hail suppression, we concluded that the most effective graupel/hail production source terms are $P_{\text {IACRG }}, P_{S A C R G}$, and $P_{\text {GFR }}$ (Accretion of rain by cloud ice produces graupel, Accretion of rain by snow produces graupel, and Probabilistic freezing of rain to form graupel) before seeding and they are $P_{G D R Y}$ and $P_{G W E T}$ (Dry growth of graupel and wet growth of graupel) after seeding as shown in Figures $9 \mathrm{a}$ and $9 \mathrm{~b}$. The amounts of graupel/hail production source terms are one tenth after seeding. We have observed that the most effective sink term is $P_{G M L T}$ (Melting of graupel to form rain) before seeding and it is $P_{G S U B}$ (Sublimation of graupel) after seeding as shown in Figures 10a and 10b. After seeding, graupel source terms reduce strongly and this causes to decrease mixing ratio of graupel.

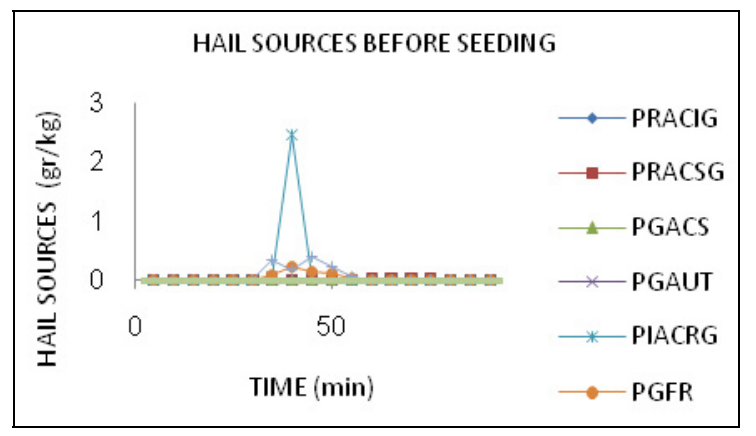

(a)

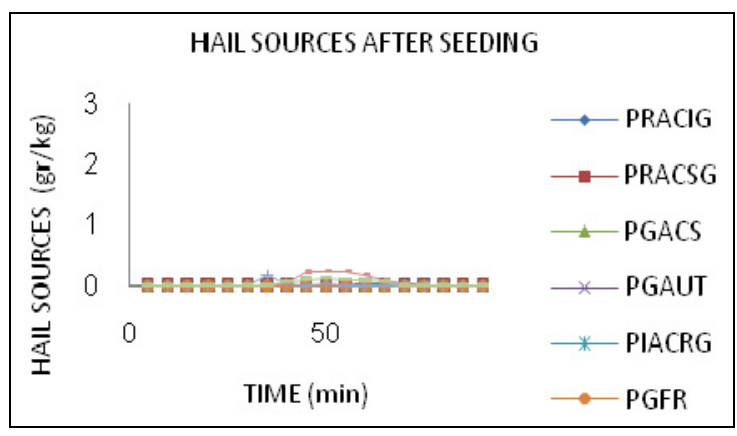

(b)

Figure 9. Comparison of the hail producing source terms (a) before seeding and (b) after seeding

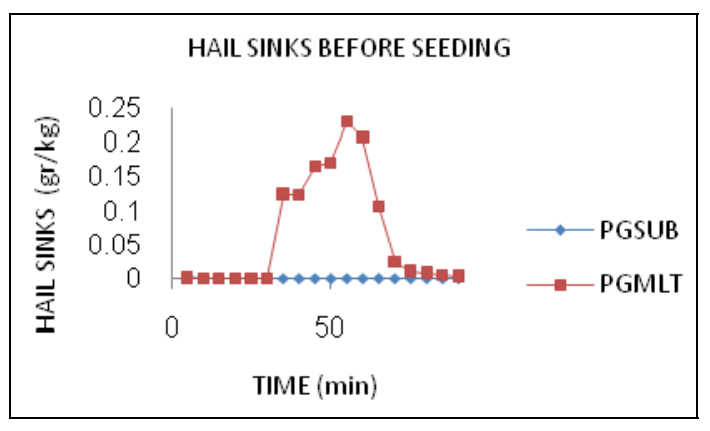

(a)

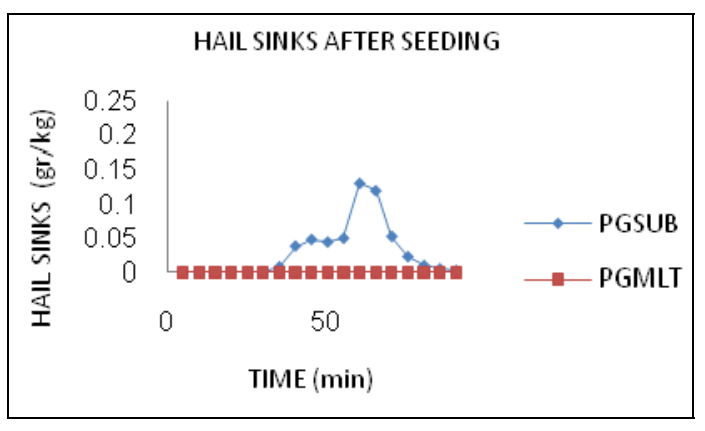

(b)

Figure 10. Comparison of the graupel/hail sink terms (a) before seeding and (b) after seeding

\subsection{Difference of Temperature between Cloud and Environment (TT)}

We define TT quantity as a temperature difference between cloud and environment. If TT is positive in a region, it is due to cloud temperature enhancement from condensation, deposition and freezing. Then, latent heat is released to cloud environment and, therefore, we expect cloud and precipitation in that region. Moreover, if TT becomes negative in the region, it means that cloud temperature has decreased due to evaporation, sublimation, snow and graupel/hail melting; therefore, cloud and precipitation would not be expected.

Comparison of Figures 11a and $11 \mathrm{~b}$, shows that the maximum value of TT is $4.09^{\circ} \mathrm{C}$ before seeding and it is $3.27^{\circ} \mathrm{C}$ after seeding. This temperature difference between before and after seeding $\left(0.82{ }^{\circ} \mathrm{C}\right)$ is due to reducing of exothermic processes, for example, $P_{I A C R}, P_{S A C R}, P_{G F R}, P_{R A C S}$, and $P_{G A C S}$ (Accretion of rain by cloud ice, accretion of rain by snow produces snow or graupel, probabilistic freezing of rain to form graupel, accretion of snow by rain, and accretion of snow by graupel) and enhancement of endothermic processes, for example, $P_{G S U B}, P_{I M L T}, P_{S A C W}$, and $P_{G A C W}$ (Sublimation of graupel, melting of cloud ice to form cloud water, accretion of cloud water by snow, and accretion of cloud water by graupel), and, therefore, release more heat to environment before seeding. Thus, it causes higher temperature difference between cloud and environment. 


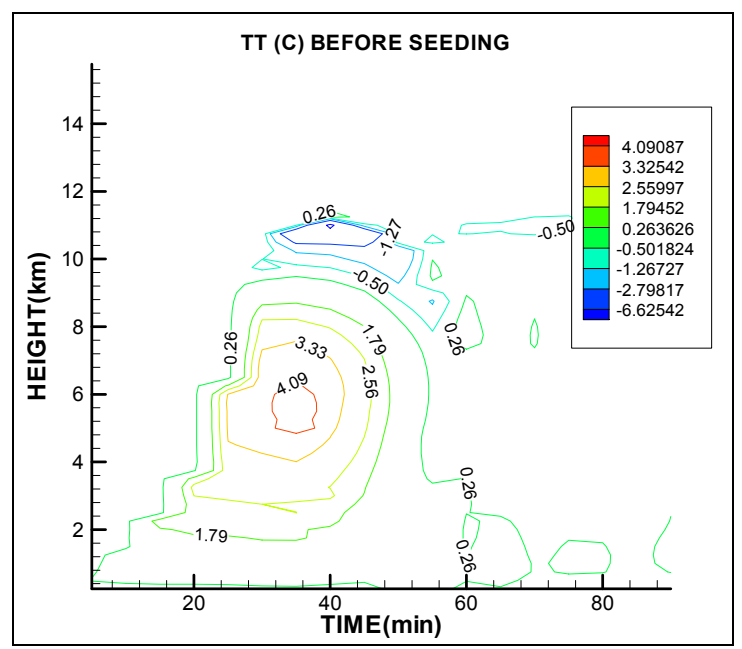

(a)

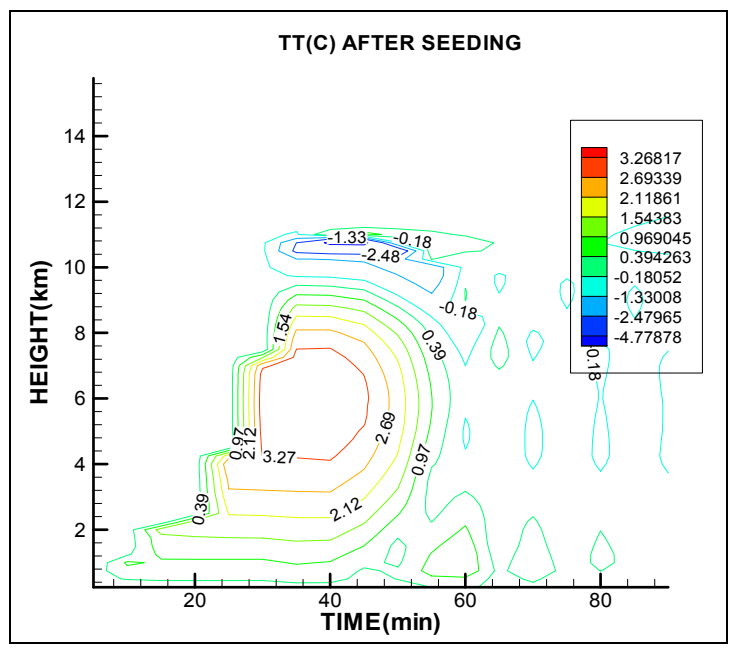

(b)

Figure 11. Comparison of the temperature difference between cloud and environment ("c) (a) before seeding and (b) after seeding

\subsection{Rainfall Intensity at Ground Surface (GPR)}

GPR quantity is the rate of rainfall intensity (PR) at ground surface and Figure 12 show the temporal variation of GPR before and after seeding. This figure shows that the maximum value of GPR is $134 \mathrm{~mm} / \mathrm{h}$ in $57 \mathrm{~min}$ after seeding. This quantity increases about $20 \mathrm{~mm} / \mathrm{h}(20 \%)$ after seeding respect to before seeding and it occurs $5 \mathrm{~min}$ later. These differences are due to enhancement of rain water source terms and amount of snow and reducing of rain water sink terms.

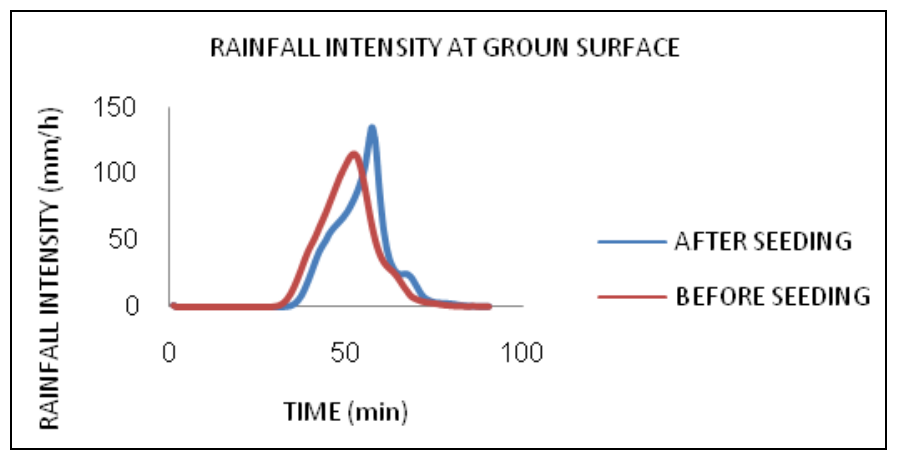

Figure 12. Rainfall intensity at ground surface before and after seeding

\section{Discussion and Conclusion}

In this paper, effects of cloud seeding by $\mathrm{AgI}$ are simulated in one dimensional cloud model. AgI introduced into the cloud at height about $6.5 \mathrm{~km}$ above the surface, within 30 minutes after cloud formation and with mixing ratio about $2.5^{*} 10^{-9} \mathrm{gg}^{-1}$. The effect of cloud seeding on microphysical quantities was quite significant and figures showed the differences in cloud hydrometer parameters between the seeded and unseeded cloud.

After seeding, heterogeneous nucleation of $\mathrm{AgI}\left(P_{N U H}\right)$ enhanced the cloud ice and this lead to increase accretion of rain by cloud ice to produces snow, transformation of cloud ice to snow through Bergeron process, and autoconversion of cloud ice to form snow $\left(P_{R A C I S}, P_{S F I}\right.$, and $\left.P_{S A U T}\right)$. These processes convert cloud ice to snow. So cloud ice has been consumed to produce snow and they did not grow up to reach graupel/hail size, therefore accretion of rain by cloud ice and snow to produce graupel/hail and freezing of rain to form graupel/hail ( $P_{\text {IACRG }}$, $P_{S A C R G}$, and $\left.P_{G F R}\right)$ that related to growth of graupel $/$ hail decreased according to competition process of hail suppression hypothesis. The maximum values of graupel/hail mixing ratio are $7.1 \mathrm{gkg}^{-1}$ and $3.3 \mathrm{gkg}^{-1}$ before and 
after seeding, respectively. This quantity decreases $\% 53$. This graupel/hail amount reducing is considerable and has been parameterized very well in the model.

Cloud ice is formed immediately and the number increased rapidly after seeding by AgI. The cloud ice in unseeded clouds was quite low. Snow in seeded clouds formed after formation of cloud ice while snow in unseeded clouds formed slowly and was very low. It was clear that snow quantity formed by AgI is more than that formed before seeding. Thus, the cloud seeding is able to speed up the formation of cloud ice and also snow. Comparing with Guo et al. (2006) results, we reached approximately similar results. They studied effects of cloud seeding by AgI using a 3D cloud model, and showed that snow in seeded clouds forms at 1-2 min after formation of cloud ice and at about $10 \mathrm{~min}$ after the model initialization, while snow in unseeded clouds forms at also about $80 \mathrm{~min}$ after the model initialization.

After seeding by increasing in melting of snow and cloud ice and reduction in accretion of rain by cloud ice and snow to produces graupel/hail and freezing of rain to form graupel/hail, rainfall enhanced about $\% 20$.

Zhen and Heng Chi (2010) used a three-dimensional mesoscale model MM5 with a two-moment cloud scheme to test the effects of seeding stratiform clouds on the accumulated rain at the surface. Similarly to our results, Zhen and Heng Chi (2010) model results indicated that seeding caused extra-area effects that increased precipitation by $5 \%-25 \%$. For stratiform clouds with silver iodide seeding in the supercooled region, the response of cloud microphysics to seeding was closely related to the transport of the seeding agent. The seeded case produced extra ice and snow in the peripheral regions of the clouds because of the effect of the induced nucleation that was caused by seeding the cloud. Deposition nucleation was the most efficient mechanism for additional cloud ice formation.

The graupel/hail formation and effect of AgI seeding, graupel/hail reduction due to activation of Bergeron process has been demonstrated in the new developed hail suppression model very well. Consequently the model has showed AgI cloud seeding could reduce hail fall and enhance rainfall and achieve graupel/hail risk management to decrease induced destruction. Moreover, AgI seeding reduced exothermic processes and increasing evaporation, sublimation, snow and graupel/hail melting, temperature difference between cloud and environment reduced $0.82^{\circ} \mathrm{C}$.

Although AgI seeding simulated in one dimensional model but this model could demonstrated the seeding effect on water substances as well as seeding effects in mesoscale models.

Finally, this work is the first step toward understanding the effects of cloud seeding using AgI in one dimensional cloud model; however, future work must be done to compare with homogeneous seeding agents such as Liquid Carbon Dioxide. Moreover, it is useful to test the effects of seeding agent on precipitation in mesoscale model to demonstrate the microphysical and dynamical interactions accurately.

\section{References}

Asai, T., \& Kasahara, A. (1967). A Theoretical Study of the Compensating Downward Motions Associated with Cumulus Clouds. J. Atmos. Sci., 24, 487-496. http://dx.doi.org/10.1175/1520-0469(1967)024<0487:ATSO $\mathrm{TC}>2.0 . \mathrm{CO} ; 2$

Garstang, M., Bruintjes, R., \& Serafin, R. (2005). Weather Modification Finding Common Ground. Bull. Amer. Meteor. Soc., 86, 647-655. http://dx.doi.org/10.1175/BAMS-86-5-647

Guo, X., Zheng, G., \& Jin, D. (2006). A Numerical Comparison Study of Cloud Seeding by Silver Iodide and Liquid Carbon Dioxide. J. Atmos. Res., 79, 183-226. http://dx.doi.org/10.1016/j.atmosres.2005.04.005

Hsie, E. Y., Farley, R. D., \& Orville, H. D. (1980). Numerical Simulation of Ice-Phase Convective Cloud $\begin{array}{lllll}\text { Seeding. } & \text { Appl. } & \text { Meteor., } & \text { 950-977. }\end{array}$ http://dx.doi.org/10.1175/1520-0450(1980)019<0950:NSOIPC $>2.0 . C O ; 2$

Jamali, J. B., \& Javanmard, S. (2003). Parameterization of Microphysical and Dynamical Processes of Rainfall in Thunderstorm Cloud Model. IR. J. Phys., 3(3), 185-198.

Jamali, J. B., Javanmard, S., \& Fateh, Sh. (2010). Investigating About Hail Event in Iran and Methods of Control and Hail Suppression. $14^{\text {th }}$ Iranian Geophysics Conference. Iran. Tehran.

Javanmard, S. (1995). Improvement Ogura- Takahashi's numerical thunderstorm model. M. S. Thesis. Faculty of Science. Kyushu Univ. Japan.

KarimPirhayati, M. (2010). Investigation on cloud seeding effect on natural precipitation process using cloud physics mumerical model. M. S. Thesis. Faculty of Science. Zanjan Univ. Iran. 
Lin, Y. L. Farley, H. D., \& Orville, H. D. (1983). Bulk Parameterization of Snow Field in a Cloud Model. J. Climate appl. Meteor, 23, 1065-1092.

Ogura, Y., \& Takahashi, T. (1971). Numerical Simulation of the Life Cycle of a Thunderstorm Cell. Mon. Wea. Rev., 99, 895-911. http://dx.doi.org/10.1175/1520-0493(1971)099<0895:NSOTLC $>2.3 . C O ; 2$

Orville, H. D. (1996). A Review of Cloud Modeling in Weather Modification. Bull. Am. Meteorol. Soc., 77, 1535-1555. http://dx.doi.org/10.1175/1520-0477(1996)077<1535:AROCMI>2.0.CO;2

Schaefer, V. J. (1965). The Production of Ice Crystals in a Cloud of Supercooled Water Droplets. Sci., 104, 457-459. http://dx.doi.org/10.1126/science.104.2707.457

Simpson, J., Simpson, R. H., Andrews, D. A., \& Eaton, M. A. (1965). Experimental Cumulus Dynamics. Rev. Geophys., 3, 387-396. http://dx.doi.org/10.1029/RG003i003p00387

Vonnegut, B. (1947). The Nucleation of Ice Formation by Silver Iodide. J. Appl. Phys., 18, 593-595. http://dx.doi.org/10.1063/1.1697813

Zhen Z., \& Heng Chi, L. (2010). Numerical Simulation of Seeding Extra-Area Effects of Precipitation Using a Three-Dimensional Mesoscale Model. Atmos. Ocea. Sci., 3, 19-24. 